\title{
MICROWAVE AND INDUCTION HEATING ON FIBRE-REINFORCED CEMENTITIOUS MATERIALS FOR THE DEMOLITION OF STRUCTURES
}

\author{
R. Borinaga-Treviño ${ }^{1}$, A. Orbe ${ }^{1}$, J. Cuadrado ${ }^{1}$, Crespo, I., ${ }^{2}$, J. Norambuena-Contreras ${ }^{3}$ \\ ${ }^{I}$ Department of Mechanical Engineering, University of the Basque Country UPV/EHU, \\ Plaza Ingeniero Torres Quevedo 1, 48013 Bilbao, Spain \\ ${ }^{2}$ TECNALIA Research and innovation, Paseo Mikeletegi 7, 2009, San Sebastian, Spain \\ ${ }^{3}$ LabMAT, Department of Civil and Environmental Engineering, University of Bio-Bio, \\ Concepción, Chile
}

*Corresponding author: R. Borinaga-Treviño. Email: roque.borinaga@ehu.eus

Keywords: microwave, induction heating, demolition, concrete, fibre

\begin{abstract}
Nowadays, strengthening and refurbishing of existing structures on urban areas has gained interest in order to reduce costs by avoiding both the use of construction raw materials and the disposal of construction and demolition waste on landfill. Usually, existing structures need to be locally demolished in order to replace either the existing corroded reinforcement or strengthen the existing structure. Among all the existing demolition methods, microwave and induction heating have been proven as a good alternative to generate a local damage with little noise and dust production, which is a desirable feature when structures are in urban areas. Nevertheless, there is a lack of information about the behaviour of both damaging methods when steel fibre-reinforced concrete is involved.
\end{abstract}

In this context, this paper studies the influence of the steel fibre addition on the damaging capacity of both microwave and induction heating demolition methods. For that purpose, mortars containing two different steel fibres were added in three different proportions and exposed to microwave and induction heating technologies. With the aim of evaluating the damage caused by both heating methods, test specimens were visually checked, and mechanical properties were determined via flexural and compressive strength tests.

According to the results, cement mortar specimens exposed to either microwave or induction heating suffered a sudden, violent disintegration without noticing any previous damage on the mortar specimens. Results proved that a pressure increment on water-saturated pores caused the failure regardless of the fibre type used as a reinforcement. However, for microwave heating, the reflection of microwaves on the fibres tended to concentrate the heating effect on the specimen surface, resulting in higher surface temperatures, but lower damaging potential of the demolition method. Furthermore, similar failure mechanism was observed on oven-dried mortars exposed to microwave heating. Nevertheless, oven dried mortars exposed to induction heating suffered a highly variable, silent and controlled damage, presenting a highly varying quantity of fracture planes that decreased its flexural and compressive strengths by up to $38 \%$ and $31 \%$, respectively. 


\section{Introduction}

With the aim of reducing construction and material costs on the construction industry, reuse of old structures has gained interest. At the same time, facades, pavements, roofs, and other non-structural parts of the buildings must be frequently replaced during the refurbishing process of old buildings. In any case, mortar and concrete materials often need to be replaced in order to guarantee a minimum quality on the refurbished building. For the removal of those materials, there are numerous alternatives [1-3], which could be classified according to the demolition mechanism used: impact, cutting, shear, bursting, abrading, high water pressure and heating. On the last, flame lance, laser beam, electron beam, arc heating, highvoltage pulses, microwave heating, induction heating, and microwave-drilling are the main existing alternatives. Among the existing thermal methods, this paper studies the use of microwave and induction heating to cause a local damage on mortar specimens.

Regarding the microwave heating technology, Ong and Akbarnezhad [3] and Makul et al. [4] summarised the different uses of microwave radiation on cement-based materials. As well as other non-destructive uses, microwaves have also been used to remove contaminated superficial concrete, to provide a contactless drilling method [5] or even to improve the recycled aggregate quality by eliminating the superficial cement paste of the recovered aggregate [6-8].

Moreover, regarding induction heating technology, it is widely being studied as a healing mechanism on several bituminous materials by Norambuena-Contreras and co-workers [9], or as a non-destructive method to detect corroded rebars [10-12]. Although Kasai [2] already indicated that demolition by induction heating of the rebar is a feasible demolition technique, the topic was not further studied for a long time due to its high cost. Nevertheless, recent studies indicate that there is an increasing interest on this demolition method $[13,14]$. Anh and co-workers [13] introduced a wire mesh as a reinforcement on cementitious finish joints to ease its dismantling when required, with successful results.

Lim and Lee [14] compared induction heating demolition method to other methods based on the mechanical dismantling of the reinforced-concrete structure. They concluded that induction heating is $12 \%$ more expensive and significantly slower than the conventional crushing methods, but they also indicate that the generation of dust and pollutants is significantly reduced which could counterbalance, at least, the increase in cost. Nonetheless, there is few literature regarding the study of the behaviour of steel fibre reinforced cementitious materials subjected to induction heating.

This paper analyses the effect of using microwave or induction heating technologies as a demolition process on steel fibre reinforced mortars. On the particular, the paper analyses their influence on the mechanical properties of steel fibre reinforced cement mortars.

\section{Materials and methods}

This section describes the materials and experimental programme followed in this study.

Fig. 1 shows the different test methods used on the cement mortar specimens with, and without, steel fibres. 
a)

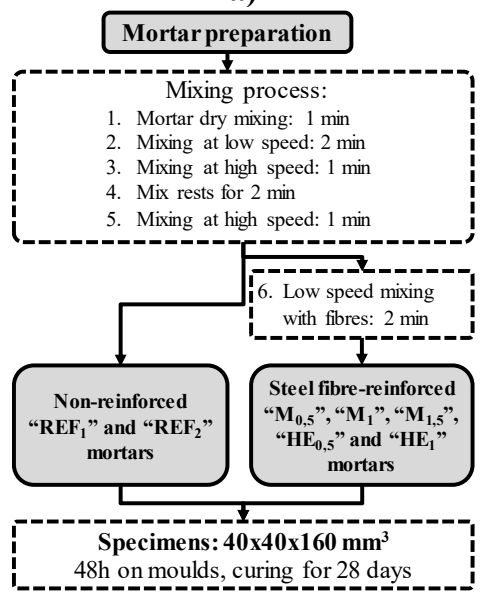

b)

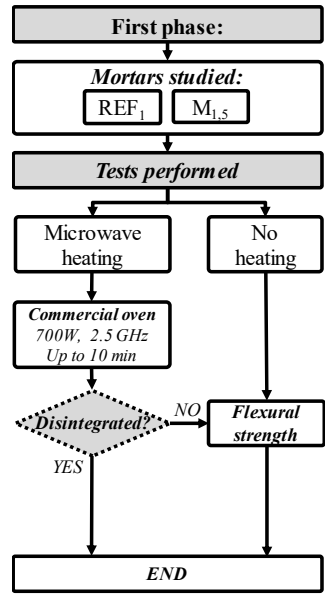

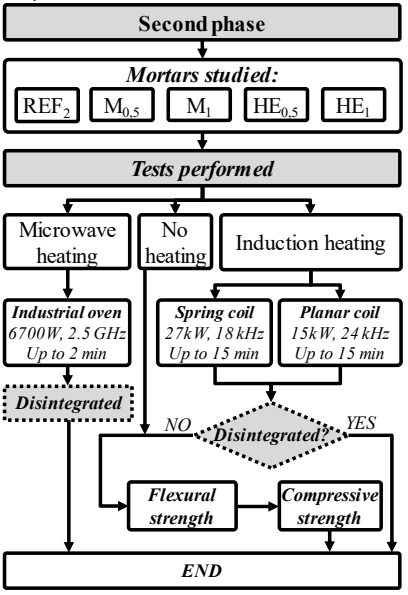

Fig. 1. Experimental programme followed in this study: a) Mixing process of the mortars and b) Tests performed on each research phase.

\section{Materials, mix proportions and specimen preparation}

On the first phase, Mapei Planitop HPC floor ${ }^{\circledR}$ mortar was used with and without the DRAMIX $^{\circledR}$ OL $13 / .20$ brass covered steel fibres $(\boldsymbol{M})$ proposed by the manufacturer as a reinforcement with the aim of evaluating the influence of the fibre presence on the damage caused by microwave heating. $\boldsymbol{M}$ fibres were $13 \mathrm{~mm}$ long and $0.21 \mathrm{~mm}$ in diameter, with a tensile strength and an elastic modulus of $2750 \mathrm{MPa}$ and $200000 \mathrm{MPa}$, respectively. The $d r y$ mortar:water:fibre proportions by weight set were the following:

(1) 1:0.12:0 for the reference $\left(\boldsymbol{R} \boldsymbol{E} \boldsymbol{F}_{1}\right)$ non-reinforced mortar.

(2) 1:0.12:0.065 for the $\boldsymbol{M}_{1.5}$ mortar, reinforced with $1.5 \%$ of $\boldsymbol{M}$ fibres by mortar volume as proposed by the manufacturer.

On the second phase, an ordinary mortar was used, as the high strength of the previous mortar could partially hinder the damaging effect expected due to both heating methods. CEM II-B (L)/32.5R cement (c) and 0/2 mm grain size limestone sand (s) were used as mortar main constituents. CRISOL 550 superplasticizer (sp) was added to all the mortars to reduce the water $(\boldsymbol{w})$ required to achieve self-compacting consistency. Finally, two types of fibres were also used to reinforce the mortar. Firstly, $\boldsymbol{M}$ fibres were again used in this second phase, since they are more appropriate to reinforce mortars due to the more reduced length and diameter. Alternatively, $\boldsymbol{H E}$ hooked structural steel fibres $(\boldsymbol{H E})$ were used, as they are used to reinforce structural concretes. $\boldsymbol{H E}$ fibres were $50 \mathrm{~mm}$ long and $1 \mathrm{~mm}$ in diameter. Five different mortars were created by varying both the fibre type and the fibre proportion used. Thus, the c:s:sp:w:fibre weight proportions set were the following:

1:3:0.01:0.5:0 for the reference $\left(\boldsymbol{R} \boldsymbol{E} \boldsymbol{F}_{2}\right)$ mortar.

$>$ 1:3:0.01:0.5:0.1 and 1:3:0.01:0.5:0.2 for the $\boldsymbol{M}_{0.5}$ and $\boldsymbol{M}_{1}$ mortars, reinforced with 0.5\% and $1 \%$ of $\boldsymbol{M}$ fibres by mortar volume, respectively.

$>$ 1:3:0.01:0.5:0.1 and 1:3:0.01:0.5:0.2 for the $\boldsymbol{H} \boldsymbol{E}_{0.5}$ and $\boldsymbol{H} \boldsymbol{E}_{\boldsymbol{1}}$ mortars, reinforced with $0.5 \%$ and $1 \%$ of $\boldsymbol{H E}$ fibre by mortar volume, respectively. 
All the tests were carried out in $40 \times 40 \times 160 \mathrm{~mm}^{3}$ prismatic test specimens prepared in compliance with EN 1015-10 [16]. The mortar mixing was similar for all the mortars studied. During the first 24 hours, test specimens were cured on moulds under ambient laboratory conditions. After removing the moulds, test specimens were submerged in water at $20^{\circ} \mathrm{C}$ for 27 days in order to reach 28 days curing age.

\section{Heating of specimens via microwave radiation}

It is known that microwave heating penetration depth on cementitious materials mainly depends on the material dielectric properties and on the heating frequency used [3]. The higher the frequency, the more superficial and local is the heating effect. At the same time, the higher the water content, the higher both the dielectric constant and the loss factor. In this way, for lower frequencies, microwaves cause the disaggregation of the cementitious material by increasing the pore water pressure until its internal collapse, while for higher frequencies, the fracture is more superficial and caused by the high thermal gradients generated. With that in mind, specimens exposed to microwave heating were oven-dried for $72 \mathrm{~h}$ at $105^{\circ} \mathrm{C}$. Afterwards, microwave ovens, with a power of $700 \mathrm{~W}$ and $6700 \mathrm{~W}$, and a frequency of $2.5 \mathrm{GHz}$, were used to ensure a uniform heating of the specimens [6,17]. Six test specimens were heated via microwave for $10 \mathrm{~min}$ and compared to another six nonheated samples. During the heating time, test specimens were surrounded by rockwool insulation and silicone moulds to protect the microwave heater from possible explosions.

\section{Heating of specimens via electromagnetic induction}

As opposed to microwave heating, non-reinforced cementitious materials are usually immune to induction heating as their ferromagnetic material content is negligible. With that in mind, ferromagnetic additives such as steel bars and steel fibres are frequently added into the cement matrix. These materials could be heated via electromagnetic induction. Thus, mortar could be indirectly heated mainly in the areas where the ferromagnetic material is, providing a way of triggering a local, selective mortar cracking. As for the microwave heating, there are two main thermal mechanisms that could fracture the mortar. Firstly, mortar could be damaged by increasing the pore water pressure until its internal collapse. Also, mortar could also be broken due to internal stress caused by excessive thermal gradients. Oven-dried and water saturated $\boldsymbol{M}_{0.5}, \boldsymbol{M}_{1}, \boldsymbol{H} \boldsymbol{E}_{0.5}$ and $\boldsymbol{H E}_{1}$ mortars were exposed to two different induction heating processes as it is summed up in Fig. 2: 
a)

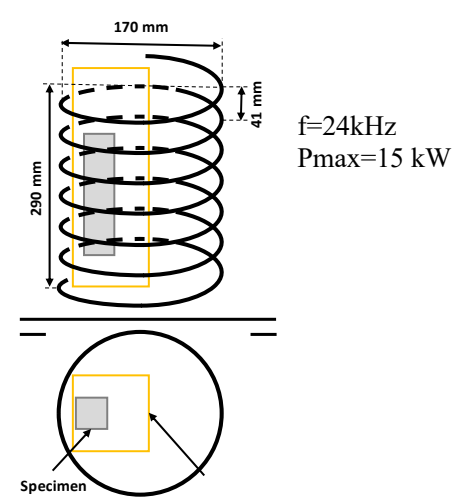

b)

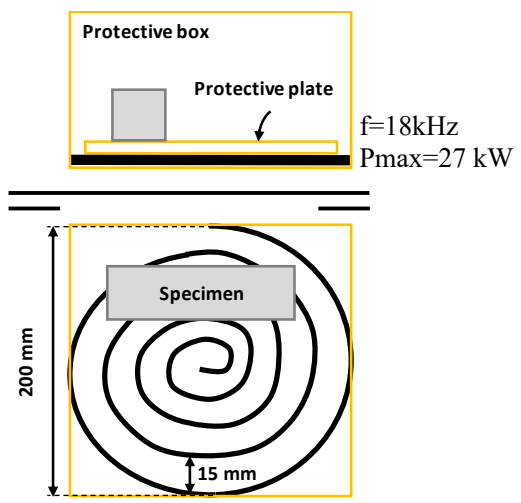

Fig. 2. Disposition of the specimens on each induction heating equipment: a) spring inductor, and b) spiral planar inductor.

\section{Flexural and compressive strength tests}

Flexural and compressive strength tests were carried out according to the standard EN 101511 to determine the damage caused by the thermal process applied on each test specimen. Flexural test was displacement-controlled, with a displacement speed ratio set to 0.5 $\mathrm{mm} / \mathrm{min}$. Compressive test was load controlled, with a load increment force ratio of $0.5 \mathrm{kN} / \mathrm{s}$. Finally, for each mortar type and thermal process combination studied, the resulting flexural strength was calculated as the mean value of all the specimens available on each case.

\section{Results and discussion}

\section{Microwave heating effect on the mechanical properties of the hardened mortar}

Fig.3a shows the flexural strength of the $\boldsymbol{R E} \boldsymbol{F}_{1}$ and $\boldsymbol{M}_{1.5}$ mortars with, and without the microwave heating process carried out at $700 \mathrm{~W}$ and $2.5 \mathrm{GHz}$. For the $\boldsymbol{R E F}_{1}$ mortar, flexural strength of the non-heated mortar samples was $14.9 \mathrm{MPa}$, while the value after $10 \mathrm{~min}$ of heating could not be measured as the specimens violently collapsed after 300-400s (Fig. 3b). To determine if the flexural strength suffers a gradual decrease until its failure, 6 more $\boldsymbol{R} \boldsymbol{E} \boldsymbol{F}_{\boldsymbol{1}}$ specimens were also microwave heated during $4 \mathrm{~min}$. In this case, flexural strength was reduced to nearly $50 \%$ of the value observed for the non-heated samples. 
a)

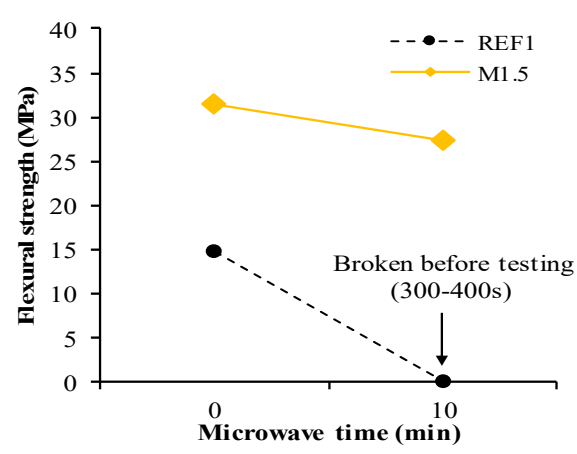

b)

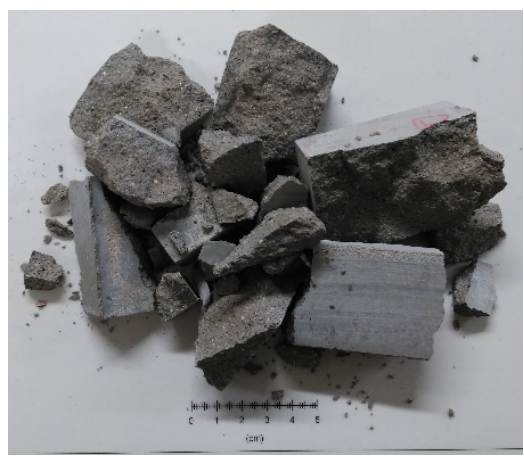

Fig. 3. Influence of microwave heating on the hardened mortar: a) evolution of the flexural strength with the microwave heating time; b) $\mathrm{REF}_{1}$ mortar situation after its disaggregation

$$
\text { (300-400s). }
$$

Additionally, surface temperature of the specimens was also measured by using a "Fluke 561 " infrared thermometer. As the $\boldsymbol{R E F}_{1}$ mortars collapsed before reaching the $10 \mathrm{~min}$ initially set, collapsed non-reinforced mortar sample temperatures were determined immediately after cancelling the heating process. According to the results, it seems that in $\boldsymbol{R E} \boldsymbol{F}_{1}$ the temperature reached on the newly exposed surfaces was higher than the $250.9^{\circ} \mathrm{C}$ measured, as there was a time lapse of 15-30s between the occurrence of the collapse and the moment when the photographs were taken. Besides, the microwave walls were wet when the collapse of the $\boldsymbol{R E} \boldsymbol{F}_{1}$ mortars occurred, but dry when the $\boldsymbol{M}_{1.5}$ mortars were heated, which indicated that the main cause of the collapse for the $\boldsymbol{R} \boldsymbol{E} \boldsymbol{F}_{1}$ mortars was the rise of the pore water (vapor) pressure as there was a sudden release of water in the disaggregation process. Regarding $\boldsymbol{M}_{1.5}$ mortar, the temperature observed on the surface of the specimens was $348.7^{\circ} \mathrm{C}$, thus significantly higher than that observed on the $\boldsymbol{R E} \boldsymbol{F}_{\boldsymbol{1}}$ mortar. Despite the higher surface temperature, specimens were not significantly damaged, as the flexural strength was only reduced by $13 \%$ due to all the heating process. As the steel reflects the microwave radiation [3], most of the heating effect was focused on the specimen surface for the $\mathrm{M}_{1.5}$ mortar. Therefore, a high temperature gradient was generated on the surface, but not enough to cause the collapse with the power of $700 \mathrm{~W}$ applied. However, some specimens were also tested in a more powerful microwave $(6700 \mathrm{~W}$, nearly 10 times the power previously used). In this case, both mortar types broke after a heating time of 90-120s. For the $\boldsymbol{R E F}_{\boldsymbol{1}}$ mortar, the appearance of the specimen after the collapse was similar to that observed previously. However, $\boldsymbol{M}_{1.5}$ mortars tended to suffer little collapses sequentially. With the first explosion, there was a superficial removal of the material surrounding the $40 \mathrm{~mm}$ edges of the specimens. After a few seconds, a second explosion occurred, removing more material on the newly created surface. In short, collapses were more controlled and gradual than that observed for the non-reinforced mortars.

\section{Induction heating effect on the mechanical properties of the hardened mortar}

Fig. 4 shows the flexural and compressive strength of the oven-dried mortars as a function of the heating treatment used. According to the results obtained, both flexural and compressive strengths were clearly reduced due to the induction heating when spring 
inductor was used. For the mortars reinforced with $\boldsymbol{H E}$ fibres, flexural strength and compressive strength were reduced by up to $38 \%$ and $31 \%$, respectively. In addition, the strength reduction could be considered similar for both fibre proportions studied. In the same way, mortars reinforced with $\boldsymbol{M}$ fibres suffered a decrease on the flexural and compressive strengths of up to $35 \%$ and $15 \%$, respectively. However, after a visual inspection of both mortar types, it is clear that the damage is only visually appreciable on the $\boldsymbol{H E}$ mortars (see Fig. 5a), as the $\boldsymbol{M}$ mortars did not present any surface crack that could indicate this weakening effect caused by induction heating. Due to their greater fibre content for the same volume due to their smaller length, fibres were more effective for crack arrest. Accordingly, $\boldsymbol{H E}$ mortars subjected to flexural strength test with visual cracks tended to break following the previously generated crack paths (see Fig. 5b).

a)

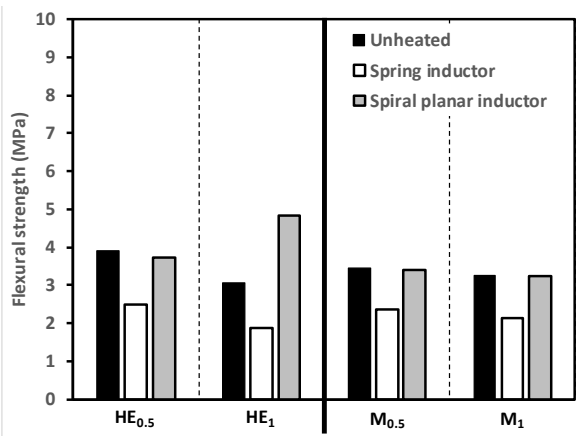

b)

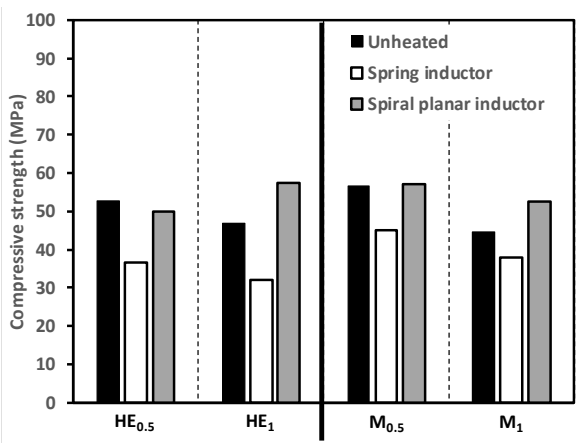

Fig. 4. Influence of the fibre type, proportion and induction heating process on mechanical properties of the hardened mortar: a) flexural strength; b) compressive strength.

Moreover, regarding the results obtained on oven-dried specimens heated by a spiral planar inductor, results are not conclusive. Spiral planar inductor is not as effective as the spring inductor, since it only affects one face of the specimens, instead of enclosing it. For both $\boldsymbol{H E}$ and $\boldsymbol{M}$ mortars, reductions of flexural strength and compressive strength are negligible. Even in some cases, an increase on the mechanical properties of the tested specimens was observed, which is attributed to the known statistical variations of the cementitious matrix and to the randomness of the fibre distribution and orientation.

a)

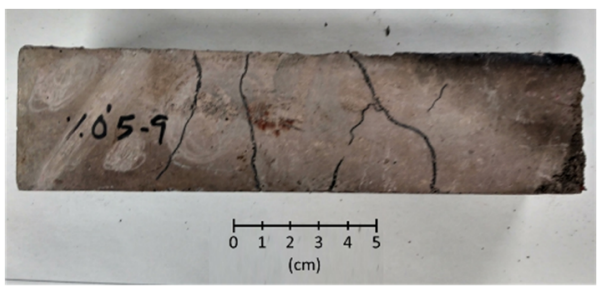

b)

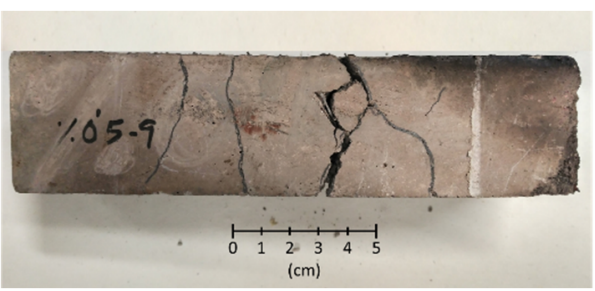

ortar: a) after spring induction heating; b) after flexural strength test.

Finally, one water saturated mortar specimen per mix was heated with the spiral planar inductor. In this case, $\boldsymbol{H E}_{\boldsymbol{1}}$ and $\boldsymbol{M}_{\boldsymbol{1}}$ mortars broke after heating them for $2 \mathrm{~min}$ and $9 \mathrm{~min}$, respectively. Consonant with the microwave heated specimens, the excessive pore water 
pressure generated caused the sudden release of the vapour generated during the heating process. Thus, both specimens suffered a sudden, very violent collapse due to the high porewater pressure. Fig. 6 shows the appearance of the $\boldsymbol{H E}_{\boldsymbol{1}}$ specimen. $\boldsymbol{M}_{\boldsymbol{1}}$ specimen is not shown as it was completely disintegrated during the process. Nevertheless, $\boldsymbol{M}_{\boldsymbol{I}}$ test specimen also took a significantly higher heating time that $\boldsymbol{H} \boldsymbol{E}_{\boldsymbol{l}}$ mortar, which is attributed to the higher specific surface of the fibres related to their smaller diameter, which makes the coupling of the fibres with the inductor less efficient. For the $\mathrm{M}$ fibres, the heating efficiency would increase by increasing the frequency of the induction equipment. Anyway, water saturated $\boldsymbol{M}_{0.5}$ and $\boldsymbol{H} \boldsymbol{E}_{0.5}$ test specimenmortars did not explode, which indicated the importance of the fibre content on the whole process.

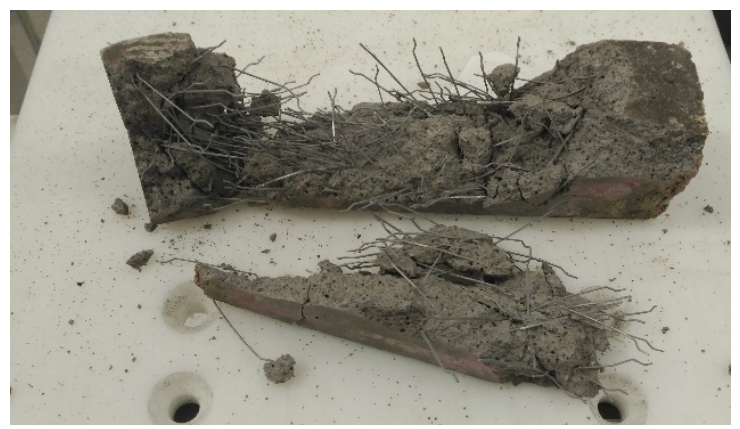

Fig. 6. Appearance of the water saturated $\mathrm{HE}_{1}$ mortar after 2 min under induction heating.

\section{Conclusions}

This paper analysed the effect of using microwave or induction heating as a potential demolition thermal process on steel fibre-reinforced mortars. The influence of both heating technologies on the mechanical properties of steel fibre reinforced mortars was studied. For that, non-reinforced mortars were compared to mortars with the same constituents and proportions, but with the addition of two different types of fibres (Hooked structural steel fibres and brass covered steel needles) in different proportions $(0.5 \%$ and $1 \%$ and $1.5 \%$ by mortar/vol.). Based on the results obtained, the authors reached the following conclusions:

With respect to the microwave heating demolition method:

$>$ For a heating power and a frequency of $700 \mathrm{~W}$ and $2.5 \mathrm{GHz}$, non-reinforced mortars collapsed after $300-400$ s heating time, because of the high pore-water pressure generated during the heating process, causing a sudden, explosive collapse, even when the specimens were previously oven-dried.

$>$ For the same heating power and frequency combination, mortars reinforced with brass covered steel fibres did not collapse and suffered a negligible reduction (13\%) of their flexural strength. Fibres tended to concentrate the heating effect on the specimen surface due to their microwave shielding effect, which resulted in surface temperatures $50 \%$ higher than those observed on the non-reinforced mortars.

$>$ Both mortars collapsed after increasing the heating power to $6700 \mathrm{~W}$. The failure mechanism on non-reinforced mortar was similar to that previously observed. For the mortar reinforced with brass-covered steel fibres, failure mechanism was the same but occurred via consecutive superficial removals nearby the shorter edges of the specimens. 
With respect to the induction heating demolition method:

$>$ On oven-dried specimens, both flexural and compressive strengths were only clearly reduced due to the induction heating when spring inductor was used. The damage was only visually appreciable on the mortars reinforced with hooked structural steel fibres.

$>$ On water-saturated specimens, the fibre proportion used had a significant influence on the damage observed. No matter the fibre type used, mortars with the lowest fibre proportion did not suffer significant damage. However, damage on the mortars with the highest fibre proportion suffered a similar failure mechanism to that observed on nonreinforced mortar samples exposed to microwave heating. In this case, the collapse was even more violent and effective to that observed with microwaves.

\section{Acknowledgements}

This work has been partly financed within the European Horizon 2020 Joint Technology Initiative Shift2Rail through contract no.730841 (IN2TRACK) and no. 826255 (IN2TRACK2). This work was also co-financed with the projects Elkartek 2018 ref. KK2018/00073 (GOLIAT) and Elkartek 2019 ref. KK-2019/00023 (GOLIAT2). The authors also wish to thank the Basque Government for financial assistance through IT919-16.

\section{References}

[1] Lindsell P. Demolition Techniques for Concrete Structures. In: Kreijger PC, editor. Adhesion Problems in the Recycling of Concrete, Boston, MA: Springer US; 1981, p. 201-215.

[2] Kasai Y. Demolition of concrete structure by heating. Concr Int 1989;11:33-8.

[3] Ong K, Akbarnezhad A. Microwave-Assisted Concrete Technology: Production, Demolition and Recycling. 1st ed. 6000 BROKEN SOUND PARKWAY NW, STE 300, BOCA RATON, FL 33487-2742 USA: CRC Press TAYLOR \& FRANCIS GROUP, 2015.

[4] Makul N, Rattanadecho P, Agrawal DK. Applications of microwave energy in cement and concrete - A review. Renewable Sustainable Energy Rev 2014;37:715-33.

[5] Jerby E, Aktushev O, Dikhtyar V. Theoretical analysis of the microwave-drill near-field localized heating effect. J Appl Phys 2005;97.

[6] Akbarnezhad A, Ong KCG, Zhang MH, Tam CT, Foo TWJ. Microwave-assisted beneficiation of recycled concrete aggregates. Constr Build Mater 2011;25:3469-79.

[7] Tsujino M, Noguchi T, Kitagaki R, Nagai H. Ompletely recyclable concrete of aggregate-recovery type by using microwave heating. J Struct Constr Eng 2011;76:2239.

[8] Menard Y, Bru K, Touze S, Lemoign A, Poirier JE, Ruffie G et al. Innovative process routes for a high-quality concrete recycling. Waste Manage 2013;33:1561-5.

[9] Norambuena-Contreras J, Garcia A. Self-healing of asphalt mixture by microwave and induction heating. Mater Des 2016;106:404-14.

[10] Kobayashi K, Banthia N. Corrosion detection in reinforced concrete using induction heating and infrared thermography. J Civ Struct Health Monit 2011;1:25-35.

[11] Baek S, Xue W, Feng MQ, Kwon S. Nondestructive Corrosion Detection in RC Through Integrated Heat Induction and IR Thermography. J Nondestr Eval 2012;31:18190.

[12] Liu L, Zheng D, Zhou J, He J, Xin J, Cao Y. Corrosion detection of bridge reinforced concrete with induction heating and infrared thermography. Int $\mathrm{J}$ Rob Autom 2018;33:379-85. 
[13] Ahn J, Noguchi T, Kitagaki R. Disassembly properties of cementitious finish joints using an induction heating method. Mater 2015;8:2433-53.

[14] Lim M, Lee JS. Economic feasibility of the induction heating method for dismantling structures: Analysis of reinforcement recovery costs based on required demolition equipment. Int J Appl Eng Res 2017;12:13077-83.

[15] UNE-EN 1015-10. Methods of Test for Mortar Masonry. Part 10: Determination of Dry Bulk Density of Hardened Mortar, . 2007.

[16] Norambuena-Contreras J, Gonzalez-Torre I. Influence of the microwave heating time on the self-healing properties of asphalt mixtures. Appl Sci 2017;7. 